\title{
A Prestação de Serviços Turísticos e o Código de Defesa do Consumidor: Um Estudo das Reclamações de Turistas ao Procon ${ }^{1}$
}

\section{Clándia Ogata Takio²}

Rl:SUM(): listudo que enfoca a questão da detesa dos direitos do consumidor-lurista frente aos principais forneedores: hoteleiros, Cias. de transporte aćreo e rodoviário e, anda, as agêneias c/ou operadoras de Turismo. Aborda as experiêneias e alguns casos especificos de ocorrência de má prestação de serviços, o seu encaminhamento e solução no PROCON/SP e conclui com a apresentação de algumas propostas que buscam diminuir os incidentes entre empresas e turistas.

PALAVRAS-CHAVE: Serviços turisticos; delesa do eonsumidor; PROC(ON/São Paulo/Brasil.

ABSTRACT: This study focalizes the defense of the tourist consumers rights towards the main firmisher. companies: holels, air service, land transportation, and also, travel agencies and tour operators. It mentions the experiences and some specific cases in which there where incidents of had louristic service, moreover the process of conducting and the results of problems

SP. The search concludes with the presentation of some proposals to reduce the mumber of incidents between the companies and the tourists.

KEY WORDS: Touristic services; defense consumer; PROC.ON/São Paulol Brazil.

\footnotetext{
1. Sintese do Trabalho de C'onclusão de Curso defendido na Escola de Comunicações e Artes da Unviersidade de São P'aulo, em novembro de 1995

2. Bacharel em Turismo pela EC'A-USP. Técnica do I'rocon - São P'aulo

End. para corresp.: Av' Parada P'into, 3420, Bloco 4, ap. 125-1 Horto Florestal-02611-001-São P'aulo - SI' - Brasil.
} 


\section{Introduçāo}

O Código de Defesa do Consumidor entrou cm vigor em 11/3/9) c. desde então, a relação entre consumidores efornecedores no Brasil tem sofrido alteraçõcs: de um lado cstá o consumidor, cada vez mais consciente de seus dircitos c mais crítico diante dos produtos c serviços que lhe são oferecidos c, do outro lado, cstào os fornecedores que tem se adaptado a esta nova realidade de mercado, adotando programas de qualidade, criando centros de atendimento ao consumidor, entre outras providências.

A Coordenadoria de Proleção c Defesa do Consumidor - Procon, órgão subordinado à Secrelaria da Justiça e da Defesa da Cidadania do Eslado de Sào Paulo, $1 \mathrm{em}$ recebendo a cada ano um número maior de queivas de consumidores insatisfeitos com os mais diversos problemas de consumo. As reclamações fundamentadas, resolvidas ou não, fazem parte do "Cadastro de Fornecedores Reclamados", lista publicada anualmente pelo órgão.

Para se encontrar as reclamações mais freqüentes, realizou-se um levantamento das mesmas contra as empresas turisticas, com base em relação publicada pelo Procon/SP referentc aos anos de 1993 e 1994. Alćm da quantificação, realizouse a análise de uma amostra destas qucisas c uma pesquisa junto às agências c/ou operadoras de lurismo sobre qualidade de atendimento. Ao final, os resultados dos dois levantamentos são confrontados, c dessa análise surgem propostas para minimizar a incidência de atritos entre este tipo de cmpresa turística c o consumidor

\section{O Procon/SP e a Defesa do Consumidor}

Em 6/5/76 foi cditado o decreto n. 789)(3/76, que criou o Sistema Estadual de Proteção ao Consumidor, vinculado à Secretaria de Economia c Plancjamento, com o objetivo de prevenir abusos entre fornecedores c consumidores, cstimular a conscientização do público e conciliar as partes connitantes. Esse decreto dispunha sobre a cstrulura do Sistcma de Proteção ao Consumidor, composto por órgãos centrais (Consclho Estadual de Proteção ao Consumidor c Grupo Exccutivo de Protcção ao Consumidor - Procon).

O Procon/SP, atualmente vinculado à Secretaria da Justiça c Delesia da Cidadania, ć composto por quatro departamentos técnicos: a Divisão de Ação Regional - DAR; Divisão de Fiscalização c Defesa do Consumidor - DFDC: 0 Centro de Estudos c Pesquisas - CEP c o Departamento de Atendimento c Orientação ao Consumidor - DAOC, sendo este último o responsível pelo atendimento direto ao público, csclarecendo dúvidas dos consumidores e realizalltdo audiências conciliatórias entre as partes.

$O$ atendimento de modo geral e simplificado é feito da seguinte forma: consumidor dirige-se ao órgão pessoalmente, por carta, fax ou telefone c cxpõe 0 seu problema de consumo. O técnico do Procon analisa a questão e contacta fornecedor solicitando esclarecimentos. Não havendo resolução do caso c confir mada a procedència destc, o problcma é cnviado para análise cm uma das scis árcas especificas que compõc a Divisão de Análise c Encaminhamento: Alimentos. Saúde. Habitação, Produtos. Servi

relacionados com as empresas turíslicas, por cremplo, sao envia

Servicos, que ira contatar consumidor e cmpresal c. caso seja necessario, realizara a audiência conciliatória na tentativa de um acordo amigável

Quando há acordo entre as partes, é realìado um termo que é homologado pelo Juizado Especial Cível. Caso não haja composição de acordo. o consumidor poderá ingressar nesse mesmo Juizado ou, se a causa ultrapassar o limitc cslipulado será orientado a ingressar na Justiça Comum.

Os desfechos das reclamações cnviadas à Divisão de Análise c Encaminhamento são publicadas anualmentc no "Cadast ro de Fornecedores Reclamados". un encarte especial do Diario (Oficial do Estacto.

A publicação segue a determinação do artigo +4 do Código de Defesa do Consumidor, que determina:

Os órgãos públicos de defesa do consumidor manterão cadastros atualizados de reclamaçōes fundamentadas contra fornecedores de produtos ou serviços, devendo publicà-la pủblica e anualmente. A divulgação indicará se a reclamação foi atendida ou não pelo fornecedor

No "Cadastro" são publicados os nomes das empresas reclamadas, qual o lipo de reclamação c se foram resolvidas ou não

Cabc ainda ressaltar que as reclamações acolhidas pelo órgão são analisadas com base cm legislações específicas (por cxemplo, Lci do Inquilinato, Plano Rcal) portarias, circulares, medidas provisórias e no Código de Defesa do Consumidor - CDC Dentre cles, o CDC ć o insırumento de maior imporlância c o mais utilizado pelos técnicos do órgão

Instituido pela lei n. 8(078, de 11/9/9), o Código de Defesa do Consumidor começou a vigorar $\mathrm{cm}$ I()/3/9) I $\mathrm{e} \mathrm{tem} \mathrm{o} \mathrm{objetivo}$

reforçando a posição do consumidor c proibindo c limitando cerlas práticas de mercado pelos formecedores. De acordo com os scus autores (Grinorer: 199) 1: 12) o CDC apresenta contcúdo c cstnutura moderna e cstá cm sintonia com a realidade do Pais. Entre suas principais inovações.

conceito amplo de fornecedor, incluindotodos os agentes cconômicos que at uam no mercado de consumo: um elenco básico de dircitos do consumidor como. por cremplo. o seu reconhecimento como parte mais fraca na relação de consumo: proteção contra desıios de quantidade c qualidade: regramento do marketing controle das práticas c cláusulas abusivas c facilitação do acesso à Justiça para o consumidor (por cremplo. Juizados Especiais Círcis) 


\section{Reclamaçōes contra Empresas Turisticas no Procon}

Análise das Empresas Turisticas Reclamadas

Nesta análise consideraram-se as seguintes empresas turisticas: as agências c/ou operadoras de turismo. os hotéis, companhias aćreas e as cmpresas de transporte rodoviario Os casos cnvolvendo reslaurantes nia foram considerados por pertencerem a área de Alimentos do Procon e possuírem legislação e fiscillização diferenciadas. enrolvendo estruturas mais complexas.

Em 1993, do tolal de 2(016 cmpresals que tiveram seus nomes publicados 110 "Cadastro", 4() cram cmpresas turisticas, distribuídas $\mathrm{cm} 24$ agencias c/ou operadoras de turismo. 9) cmpresas de transporte rodoviário. 5 hotéis e 2 companhials aćrcas.

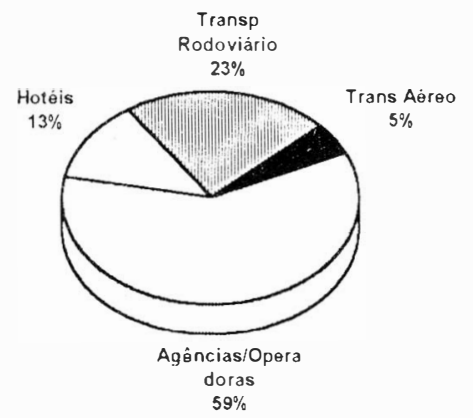

FIGURA 1 - EMPRESAS TURISTICAS RECLAMADAS EM 1993 POR TIPO DE FORNECEDOR

Já no "Cadastro" de 199ł, também com o total de 2016 cmpresas t. cmpresas turisticas foram reclamadas. dividindo-se da seguinte forma: 22 agências/operadoras de viagens; 1 () companhias aéreas: 6 hotéis e 5 cmpresals de transportc rodoviário

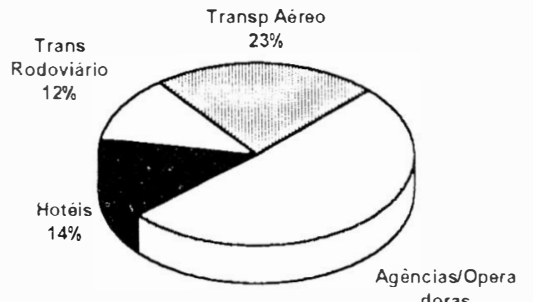

doras
$51 \%$

FIGURA 2 - EMPRESAS TURISTICAS RECLAMADAS EM 1994 POR TIPO DE FORNECEDOR

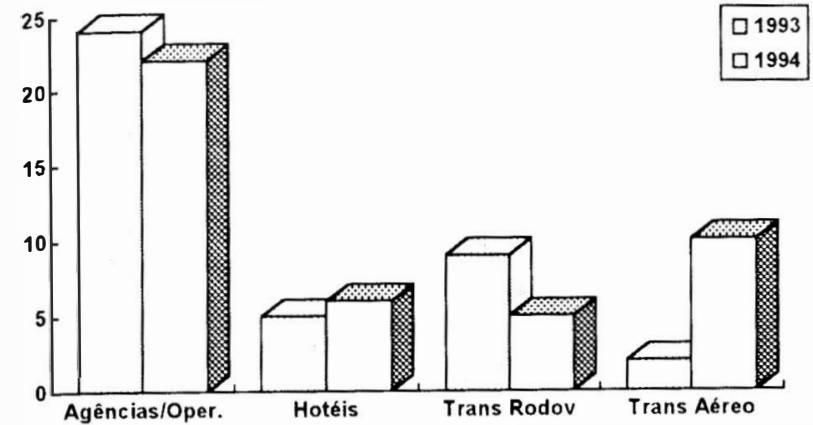

FIGURA 3 - GRÁFICO COMPARATIVO DAS EMPRESAS TURISTICAS RECLAMADAS

Em relação ao número de agências c/ou operadoras de lurismo, houve uma pequena queda de $10 \%$ de 1993 para 1994 sem, entretanto, alterar a posição deste tipo de compresa como a mais reclamada nos dois anos pesquisados.

Quanto aos hotéis, estes praticamente não sofreram alterações, mantendo quase o mesmo número de eslabelecimentos reclamados em cada ano.

Já em relação às companhias aéreas c às empresas de transporte rodoviário. há uma troca de posições: cm 1993, cnquanto apenas 2 companhias aércas sofreram reclamações, o transporte rodoviário teve 9 cmpresas reclamadas. Já $\mathrm{cm}$ 1994, o número de companhias aéreas subiu para 10, ou seja, cinco vezes mais que no anoanterior, enquanto o número de empresas de transporte rodoviáriocaiupara 5 , praticamente a metade do ano anterior.

\section{Análise das Reclamaçōes contra as Empresas Turisticas}

Em 1993, do tolal de 8() reclamações feitas contra as empresas turisticas, 59 foram dirigidas às agências e/ou operadoras: 11 às cmpresas de transporte rodoviário; 8 aos hotćis c as companhias aćrcas receberam 2 reclamações.

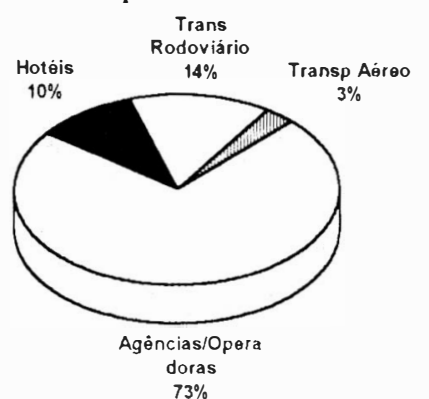

FIGURA 4-RECLAMAÇŌES FEITAS CONTRA AS EMPRESAS TURISTICASEM 1993 
Constatou-se que mais da metade $(73 \%)$ das reclamações, feitas cm lyy contra as cmpresas turísticas, foram dirigidas às agênciasc/ou operadoras de turismo

Em 199+ foran registradas 79) reclamaçoocs, divididas da seguinte formal t para as agências e/ou operadoras: 19 para as companhias. aćrcas 7 para os liotćis c 6 para as cmpresas de transporte rodoviário.

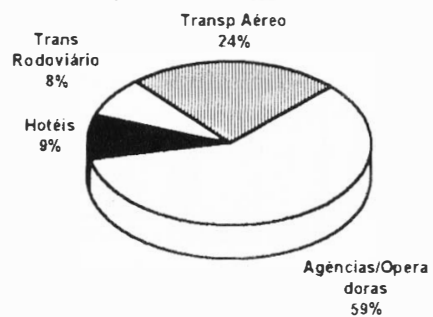

FIGURA 5-RECLAMAÇŌES FEITAS CONTRA ASEMPRESAS TURISTICASEM 1994

Novamentc as agências c/ou operadoras de turismo receberam a maioria das reclamações (5)\%). De fato, a agência c a operadora são o elo ent re os consumidores c fornecedores, respondendo inclusive legalmente pelos vicios de qualidade de hotéis, transportes e outros (o próprio CDC estabelece a responsabilidade solidária nestes casos).

\section{Análise dos Tipos de Problemas}

Nesta análise considerou-se apenas as solicitações fiundamentadas, istoć, quais os tipos de problemas mais freqüentes e se foram resolvidos ou não.

a) Agências e/ou Operadoras de Turismo

De acordo com o levantamento das reclamações no "Cadastro" de 1993. tem-se o seguinte quadro em relação a este tipo de cmpresa turística:

\begin{tabular}{l|c|c|c}
\hline \multicolumn{1}{c|}{1993} & Solucionado & Não Soluc. & Total \\
\hline A - Contrato/Proposta (cumpri/rescisảo) & 1 & 36 & 37 \\
B - Má Prestaçảo Serviço & 7 & 8 & 15 \\
C - Propaganda Enganosa/Oferta/Venda & 1 & 1 & 2 \\
D - Devoluçảo de valores & - & 2 & 2 \\
E - Cobrança (indevida/dupla) & 1 & - & 1 \\
F - Nảo Entrega Serviço & - & 1 & 1 \\
G - Estabelecimento Fechado & - & 1 & 1 \\
\hline Total & 10 & 49 & 59 \\
\hline
\end{tabular}

Quanto à resolução dos casos, as agências c/ou operadoras de turismo tiveram 59 qucixas fundamentadas, das quais 10 foram resolvidas $(17 \%)$; c 4 ) não chegaram a uma composição amigável $(83 \%)$. Dos casos não resolvidos, 30 são de uma agência que faliu. Esses casos foram cadastrados como não-cumprimento do contrato e remetidos à justiça comum, o que explica o grande percentual de não resolvidos

Em 1993 mais da metade dos problemas ( 63\% ou 37 casos) referiam-se a contratos (inclusive o caso da agência falida). Em seguida encontram-se as reclamações $(25 \%$ ou 15 casos) sobre a má prestação de serviços, os casos envolvendo propaganda enganosa e devolução de valores (3\% ou 2 reclamações de cada) c. finalizando, os problemas de cobrança, de não entrega do serviço c de estabelecimento fechado ( $2 \%$ ou 1 caso de cada).

\begin{tabular}{l|c|c|c}
\hline \multicolumn{1}{c|}{1994} & Solucionado & Não Soluc. & Total \\
\hline A - Má Prestaçảo Serviço & 12 & 11 & 23 \\
B- Contrato(cumpri/rescisảo) & 6 & 5 & 11 \\
C - Devoluçảo de Valores & 4 & - & 4 \\
D - Pagamento(atraso/dúvida) & 3 & - & 3 \\
E - Propaganda Enganosa/Oferta/Venda & 2 & - & 2 \\
F - Cobrança(indev/duplic) & 1 & - & 1 \\
G - Nảo Entrega Serviço & - & 1 & 1 \\
H - Serv Diferente Pedido & - & 1 & 1 \\
I - Serv Causou Dano ao Consumidor & - & 1 & 1 \\
\hline Total & 28 & 19 & 47 \\
\hline
\end{tabular}

b) Hotcis

Os hotéis receberam 8 reclamações em 1993, scndo cste o quadro de resolução e tipos de queixas:

\begin{tabular}{l|c|c|c}
\hline \multicolumn{1}{c|}{1993} & Solucionado & Não Soluc. & Total \\
\hline Má Prestaçảo de Serviços & 3 & 2 & 5 \\
Contrato(cumprimento/rescisảo,etc.) & 1 & - & 1 \\
Propaganda Enganosa/Oferta/Venda & 1 & - & 1 \\
Pagamento(atraso/dúvida/recusa,etc.) & - & 1 & 1 \\
\hline Total & 5 & 3 & 8 \\
\hline
\end{tabular}

Em 1993, dos problemas envolvendo hotéis 5 casos (62,5\%) foram resolvidos e 3 casos $(37 \%)$ não tiveram acordos. A reclamação mais comum foi a de má 
prestação de serviços (62\% ou 3 casos). seguida de queixas em relação aos contrallos. propaganda c pagamentos ( $12.5 \%$ cada caso $)$

\begin{tabular}{l|c|c|c}
\hline 1994 & Solucionado & Não Soluc. & Total \\
\hline Má Prestação de Serviço & - & 2 & 2 \\
Contrato (cumpri/rescisão,etc.) & - & 2 & 2 \\
Pagamento(atraso/dúvida,etc.) & 1 & - & 1 \\
Propaganda Eng/Oferta/Venda & - & 1 & 1 \\
Cobrança(indev/duplic/etc.) & - & 1 & 1 \\
\hline Total & 1 & 6 & 7 \\
\hline
\end{tabular}

Em 199) houve diminuição na resolução dos casos, apenas um obtere acordo ( $14 \%)$, cnquanto os outros 6 não foram resolvidos (86\%), como mostra 0 quadro acima.

Em 199) + de um total de 47 casos, 28 casos $(6(0 \%)$ terminaram cm acordos c cm 19 casos (4()\%) os autores foram oricntados a recorrer a outras instâncias.

Quanto aos tipos de problemas, 2.3 casos $(5() \%)$ foram $\mathrm{cm}$ relação à má prestação de serviços: 11 casos $(2.3 \%)$ com contratos: 4 casos (9\%) $\mathrm{cm}$ relação a devoluções de valores e 3 problemas (6\%) pagamentos. Com o mesmo percentual $(4 \%)$ c 2 ocorrências temos os casos de propaganda cnganosa, de cobrança indevida ou cm duplicidade, de diferenças entre o produto entregue e o solicitado e de serviços que causaram dano ao consumidor.

\section{c) Transporte Aćrco}

Em 1993. apenas 2 queixas sobre a má prestação de senviços foram registradas em relação ao transportc aćreo c ambas foram solucionadas.

\begin{tabular}{lccc}
\hline 1993 & Solucionado & Não Soluc. & Total \\
\hline Má Prestação de Serviço & 2 & - & 2 \\
\hline Total & 2 & - & 2 \\
\hline
\end{tabular}

Já cm 1994 as reclamações contra as companhias aćreas tiveram 37\% dos casos resolvidos contra $6.3 \%$ não resolvidos.
A labcla a seguir mostra como foram classificados os problemas:

\begin{tabular}{lcccc}
\hline \multicolumn{1}{c|}{1994} & Solucionado & Não Soluc. & Total \\
\hline A - Desaparecimento de mala/mercadoria & 2 & 4 & 6 \\
B - Má Prestação de Serviço & 3 & 2 & 5 \\
C - Serviço Causou Dano Pessoal/Material & - & 4 & 4 \\
D - Contrato(cumpri/rescisảo,etc.) & 1 & 1 & 2 \\
E - Devolução de Valores & 1 & - & 1 \\
F - Propaganda Enganosa/Oferta/Venda & - & 1 & 1 \\
\hline Total & 7 & 12 & 19 \\
\hline
\end{tabular}

As reclamações de perda de bagagem são as mais freqüentes. com .32\% dos casos, seguidas da má prestação de serviços com $26 \%$ dos casos. As reclamações cm que o serviço causou algum dano ao consumidor representaram $21 \%$ dos casos. os problemas com contrato representaram $11 \%$ c os casos de devolução de valores c propaganda cnganosa $5 \%$ cada.

\section{d) Transportc Rodoriário}

Em 199.3 das 11 reclamações feitas contra cmpresas de transporte rodoviário, $54.5 \%$ (6 casos) tiveram solução. enquanto $45.5 \%$ (5 casos) não foram resolvidas. A má prestação de serviços representa $46 \%$ das queivas. seguidos do desaparecimento de bagagem (.36 \%) e de danos a consumidor ( $18 \%(1)$. conforme a tabcla abaiso:

\begin{tabular}{lcccc}
\hline 1993 & Solucionado & Não Soluc. & Total \\
\hline Má Prestação de Serviços & 1 & 4 & 5 \\
Desaparecimento Mala/Mercadoria & 3 & 1 & 4 \\
Serviço Causou Dano Pessoal/Material & 2 & - & 2 \\
\hline Total & 6 & 5 & 11 \\
\hline
\end{tabular}

Em 1994 as reclamações baixaram para o total de 6. sendo $3.3 \%$ (2) resolvidas c $67 \%(4)$ sem soluçĩo junto ao Procon. No transportc aćrco o problema de critravio de bagagem lidera com $83 \%$ dos casos. seguido da má prestaçĩo de seniços $(17 \%)$ 


\begin{tabular}{lcccc}
\hline 1994 & Solucionado & Não Soluc. & Total \\
\hline Desaparecimento Mala/Mercadoria & 2 & 3 & 5 \\
Má Prestação de Serviços & - & 1 & 1 \\
\hline Total & 2 & 4 & 6 \\
\hline
\end{tabular}

\section{Casos Tipicos Solucionados}

Neste item citam-se quatro cxemplos fícticios de casos onde o consumidor possuia ampla documentação comprovando sua reclamação. o que colaborou de forma decisiva cm sua solução.

\section{Caso 1 - Má Prestação de Serviços}

O sr. Josć Ccrqucira dirige-sc à Agência de Turismo Souza para plancjar sua viagem a Europa c. ao retornar de seu passcio. alcgou ter tido muitas decepcões quanto aos serviços contratados: oônibus cra desconfortárcl. os guias despreparados c as refeições servidas cram ruins. Reclamou na Agência de Turismo Soura. a qual acusou a Operadora Santa Clara.

O sr. Cerqueira reclamou no Procon que por sua ve\% enviou uma carta a reclamada. A resposta da Agência de Turismo Souza não foi Satisfatória ca consulta se transformou $\mathrm{em}$ um processo administrativo dentro do órgão. Essa solicitaçĩo fó analisada c considerada procedente. Após contatos telefônicos sem êxito o lécnico convocou uma audiência, para a qual foram convocados : o consumidor. a Agéncia de Turismo Souza c a Operadora Santa Clara. O técnico intermediou a audiência c avaliou com o reclamante (consumidor) as propostas das reclamadas (a agencia c a operadora): um ressarcimento em dinheiro (proporcional ao que foi perdido devido à má prestação). Sendo accita a proposta. foi feito um termo entre as partes. firmando o acordo.

\section{Caso 2 - Propaganda Enganosa}

A sra. Berta Gonçalves viajou para o afastado Hotel Vale Encantado. Ao fazer a reserva no escritório localizado na Capital. a sra. Berta recebeu un follheto com fotos do Hotel Vale Encantado e através delas decidiu onde passaria seu fin de semana. Ocorreu porém que o Hotel Vale Encantado não correspondeu ao que foi visto no follhcto: a piscina estava cm construção. a sauna cstava quebrada e o chuveiro não aquecia a água de modo satisfatório. Ao retornar. a sra. Berta tentou conversar com o pessoal do escritório onde pagou a estada. mas não obtere êxito. Após reclamar no Procon, aguardou a resposta do escritório do Hotel Valc Encantado que não veio. Foi aberta a solicitação (processo administrativo) c houve Encandicncia conciliatória. en que a consumidora descjava um abatimento propora audicn fo acordado entre o reclamado e a reclamante que cla poderia utilizar mais um fim de semana, sem ônus algum.

\section{Caso 3 - Dano em Bagagem}

O sr. Carlos Farias viajou à Austrália pela Cia. Aćrea Air América. Ao etornar para o Brasil pela mesma Cia. o sr. Carlos descobriu, ao desembarcar. que sua prancha de surfe (comprada na Austrália) quebrou-se por descuido no transporO sr Carlos tentou um acordo direto com a Cia. Aćrea Air América, que lhe ofereceu o valor de US\$20,(0) por kilo (valor aviltante no caso). Recorreu ao Procon que solicitou por carta esclarecimentos da empresa. A Air Amćrica ampara-se na Convenção de Varsóvia, que realmente determina a devolução por peso 11 a proporção citada. Abriu-se a solicitação e no Setor de Serviços foi realizada proporcia conciliatória em que a cmpresa manteve a proposta da devolução por audiência conciliatoria, em que a cmpresa mantere a proposta da derónęão por Cive onde a interpretação do Código de Defesa do Consumidor-CDC pela justa reparação prevaleceu c onde a empresa foi condenada ao ressarcimento integral em valores vigentes no Brasil para o bem.

\section{Caso 4 - Extravio de Bagagem}

O sr. Geraldo Pires viajou para o interior do Paraná atrarés da Viação Zácaro. Ao descmbarcar. procurou pela TV que levava para sua mãe - a TV não estava no bagageiro tampouco foi localizada postcriormentc. Consultada a cmpresa. soube que havia uma legislação do DNER que cstipula um valor para bagagens extraviadas. Como o valor correspondia à metade do valor pago pela TV. o sr. Geraldo não accitou a proposta e reclamou junto ao Procon. Inquirida através de carta, a reclamada persistiu na proposta e o processo seguiu para o Setor de Serviços. $\mathrm{Na}$ audiência conciliatória, a Viação Zácaro acabou concordando em devolver o valor integral da TV cetraviada.

\section{Análise dos Processos}

Ao se observar que a maioria das reclamações ć contra as agências c/ou operadoras de Turismo foi feita a leitura integral c análise de uma amostragem dos processos envolvendo esse tipo de cmpresa. A leitura serviu para tornar claro o significado dos problemas apontados nas tabclas.

Foram lidos 39) processos. o que corresponde a $37 \%$ do total de reclamações 
contra as agchncias c/ou opcradoras de Turismo nos dois anos pesquisados. c observou-se screm comuns algumas queixas cm relação aos pacotes oferecidos pelas agências c/ou operadoras

Na hospedagem é comum o agente de viagens falar sobre o hotel cm que o passageiro irá hospedar-se da forma mais positiva possivel. Porém nem sempre 0 "quarto grande" tem o mesmo significado para ambos. Trata-se de conceitos subjetivos e de percepções diferentes. Ao deparar-se com um hotel três estrelas com aparência de uma pousada o consumidor se sente enganado. O mesmo ocorre con as mudanças de hotel informadas na última hora. por melhor que seja o hotel substituto. o consumidor fica preocupado com cssas trocas. uma vez que desconhece os problemas que surgem na montagem de um pacote. Pior ainda quando consumidor ć transferido para um hotel com má prestação de serviços.

Em resumo, as reclamações sobre hospedagem referem-se a hotéis diferentes dos contratados. longe das atrações do local visitado e serviços que deixam a descjar. Há casos de consumidores que. ao viajarem em alta temporada, acabaram sendo alojados cm hotéis que não possuiam camas de casal tampouco número de camas suficiente. um dos hóspedes teve que dormir em uma cama de armar.

No transporte rodoviário as reclamações são a respeito dos ônibus con categoria diferente da citada no ato de venda, além de vé́culos $\mathrm{cm}$ condições precárias (sujos, prestes a qucbrar). O despreparo dos motoristas também foi citado, por exemplo o caso do motorista que deu muitas voltas até retornar ao rotciro programado. O consumidor perde parte do passeio quando ocorrem esses atrasos.

Algumas das reclamações contra as agências de viagens dizem respeito a trocas de companhias aćreas ocorridas na última hora. O consumidor conlicce cxige companhias reconhecidamente seguras e pontuais. com qualidade de serviço c boas acomodações. Outro problema constantemente citado nos processos ć a falta de informação quanto às passagens aćreas - se são ou não cndossávcis c as suas validades. Há ainda os casos de passagens que não foram entregues a tempo do cmbarque. O problema do cxtravio de bagagens também envolve algumas agências. quando o fretamento é feito pela própria agência ou devido à responsabilidade solidária.

Por fim. o despreparo e a falta de cxperiência dos guias também geram reclamações por parı dos consumidores.

A maioria dos casos culminou $\mathrm{cm}$ audiência conciliatória, $\mathrm{cm}$ que foran! feitos diversos tipos de acordos, cvitando-se a discussão judicial. Encontram-sc cntre os acordos firmados a concessão de novas viagens para que o consumidor possa usufruir melhor o passcio: a devolução em dinheiro de trechos não voados ou de estadas não utilizadas; o fornecimento de bônus para próximas viagens ctc.

\section{Consideraçōes Finais}

O Código de Defesa do Consumidor completou cinco anos de existência c. nesse período, o respeito do fornecedor pelo consumidor tem crescido c o consumil- dor, por sua vez, tem usado cada vez mais o seu direito de reclamar. A Coordenadoria de Defesa e Proteção ao Consumidor atende cada vez mais consumidores, exigindo o que lhe é justo e tirando suas dúvidas em relação aos seus problemas de consumo do dia-a-dia. As empresas turísticas não devem se fechar ao processo de renovação que ocorre no mercado.

A pesquisa realizada junto aos "Cadastros de Fornecedores Reclamados". do Procon, reforça a proposta de que a indústria do turismo deve treinar melhor seus integrantes e melhorar a oferta de serviços e equipamentos.

O Código de Defesa do Consumidor, diferente do que muitas empresas pensam, veio com o objetivo de reequilibrar as relações de consumo, desgastadas com a produção em massa e a multiplicidade de produtos e serviços que se apresentam no dia-a-dia. Tudo isso deixa o consumidor carente de informações c em desvantagem frente ao fornecedor, mais organizado e conhecedor dos produtos e serviços que vende.

Segundo dados da Equipe de Serviços do Procon/SP, algumas agências e/ ou operadoras de Turismo têm criado seus departamentos de atendimento ao consumidor e assim tem evitado que determinados casos sejam enviados ao Juizado Especial Cível ou à Justiça Comum

Tendo em vista a diminuição dos atritos entre consumidores e fornecedores turísticos, sugerem-se as seguintes propostas:

- é necessário que o Agente de Viagens esteja atualizado quanto ao produto que está vendendo. A realização de um maior número de viagens de reconhecimento por cle aos locais vendidos ou a exibição de vídeos atualizados, além de treinamento não só na parte técnica, mas também na área de atendimento ao público com noções do novo Código de Defesa do Consumidor, poderiam ser considerados para a diminuição de problemas relacionados ao não-cumprimento da oferta e/ou propaganda enganosa. Essa falta de conhecimento do produto é que leva muitas vezes ao fornecimento de informações equivocadas

- a cobrança de melhoria e/ou manutenção da qualidade dos serviços prestados entre os parceiros - agências e/ou operadoras, hotéis e transportadoras - deve ser considerada para a melhoria da prestação de serviços ao consumidor. Deve haver a realização de visitas periódicas para a renovação de contratos de fornecimento:

- o material utilizado para promover o local a ser visitado deve ser atualizado, ou seja, a elaboração de prospectos e até de vídeos devem ser coerentes com o que realmente é ofertado. Mesmo nos jornais e demais meios de comunicação, a promoção deve ser feita de modo claro e preciso, a fim de não deixar dúvidas sobre o serviço oferecido. O Código de Defesa do Consumidor garante ao consumidor a proteção contra a propaganda enganosa ou abusiva, além de determinar que as informações devem ser claras e precisas, e na língua portuguesa; 
- der c-se considerar a implantação de uma linha dircta para o atendimento ao consumidor, com o objelivo de sanar dúvidas antes. durante e depois da viagem: além de fornecer informações sobre a documentação necessária. dicas do local c outros detallies de última hora. Uma linha direta não serve apenas para compresas de produtos, as cmpresas de serviços também podem utilizar esse sistema que não só alcude ao consumidor, mas também serve como "ouvido" da cmpresa, colhendo informações para melhorar os serviços oferecidos;

- deve ser feita uma análise do contrato cntre cmpresa c consumidor por uma equipe jurídica. Há cmpresas que possuem contratos feitos antes do Código de Defesa do Consumidor c que necessitam de uma adaptação para cvilar cláusulas que. ao final. depõcm contra a própria cmpresa. Cláusulas abusivas, que dei.iam o consumidor em desvantagem perante a cmpresa, devem estar claras c ostensivas c, ainda assim, podem ser passíveis de apreciação jurídica.

\section{Bibliografia}

GRINOVER, Ada Pellegrini et alii. 1992. Código Brasileiro de Defesa do Consumidor comentado pelos autorex. Rio de Janeiro: Forense Universitária. 713 r

NI NES, Luís Antônio. 1991 A Empresa e o Código de Délésu do ('onsumidor São l'aulo: Artpress. 12-tp

Sĩo PAUL. Secretaria da Justiça e da Defesa da Cidadania Coordenadoria de Defesa e f'roteção ao (onsumidor 1993 Cadastro de liornecedore's Reclamados do P'ROCON' - f'eriodo de 19y3. março de 19y.t. 15.

SÃ () PAUI. () Secretaria da Justiça e da Defésa da Cidadania Coordenadoria de Defesa e P'roteção ao Consumidor. 1995. Cadastro de liornecedores Reclamados do P'ROCON - P'eriodo de $109+$ março de $199514 \mathrm{p}$.

TAKIO, Cláudia (Ogata 1995. A Prestação de Sen'iços Turísticos e o (ódig̨o de Dejesa do Consumidor um estudo das

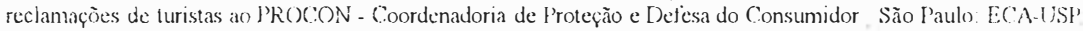

